\title{
SKIRMISHES ON THE TEMPORAL BOUNDARIES OF STATES
}

\author{
MEIR DAN-COHEN*
}

I

\section{INTRODUCTION}

Our practical life is for the most part future-oriented, concerned with what to do next. But though the future often presents daunting challenges, the past can raise more intractable ones. When two neighbors disagree about the use of a driveway, then with some ingenuity and goodwill they may be able to reach a mutually advantageous agreement. But if the source of their acrimony is that one neighbor had already slapped the other or hit him over the head, the prospects for an amicable resolution seem dimmer. Future-regarding conflicts appear at least in some respects easier to settle than past-regarding ones. Since the future is open-ended, there may be room for an accommodation that will make the bone of contention disappear. But a past event is fixed, casting a permanent shadow; it cannot be undone. This predicament, of living in the dark shadow of the past, is faced not only by individuals, but by collectivities as well. States in particular must often cope with the "dead weight" of history and address grievances whose origins lie in past mischief. How can they do that? What options are open to them?

In considering these questions, we can draw encouragement as well as guidance from recognizing that we are not in fact helpless in coping with past misdeeds. Although humanity's record in this regard is far from stellar, it is not altogether bleak. Not all disputes linger forever, and many grievances, individual as well as collective, have been successfully resolved. The issues I am addressing here are primarily theoretical, not practical. We are looking not for a new strategy, but for a new account. Given that we do in fact occasionally escape the shadow of the past, we want to better understand how we manage to do so. Greater clarity may, however, have a practical payoff as well, in perhaps increasing our rate of success. The first task, discharged in section II, is accordingly to examine some pervasive conceptions of the problem of the past and common responses to it. As I try to show, the problem has remained largely out of focus, with its difficulty either understated or overstated; consequently,

\footnotetext{
Copyright $\odot 2009$ by Meir Dan-Cohen.

This Article is also available at http://www.law.duke.edu/journals/lcp.

* Milo Reese Robbins Chair in Legal Ethics, University of California at Berkeley School of Law. I'd like to thank for their helpful comments participants in this symposium, in the Bay Area Forum for Law and Ethics (BAFFLE), and in the Tel Aviv University Legal Theory Workshop.
} 
the responses as generally conceived also appear to miss the mark, by either undershooting or overshooting it. Once the problem is in sharper focus, we can address it more effectively. In section III I introduce the notion of a state's temporal boundary and describe how changes in this boundary, analogous to the more familiar changes in territorial borders, can lift the shadow of the past and relieve past-oriented grievances. Section IV connects this conceptual framework to the distinction between history and memory as two different modalities of relating to the past. A proper understanding of a state's relationship to the past, and in particular the possibility of changes in a state's temporal boundaries, offers a way to retain historical knowledge of past wrongs without the rancor and acrimony that mark this knowledge when it assumes the form of collective memory.

II

\section{THE SHADOW OF THE PAST}

In the case of the two neighbors, as in the case of two neighboring states, the aspiration is to relieve acrimony and induce peace. But the past altercation stands in the way; it casts a dark shadow. For the peacemaking mission to succeed, we must be clearer about the nature of the obstacle presented-the shadow cast-by the past event. What is the significance of the assault, and why does it mar the neighbors' relationship? The starting point is to observe the obvious. Following the attack, bad feelings will linger, perhaps to the point of prompting further hostilities. But bad feelings do not beset the parties as a common cold might; they are not just brute facts. Rather, there is a normative dimension as well. We judge it appropriate that an assault should provoke reactive attitudes, in particular the victim's resentment. ${ }^{1}$ But why are negative responses to the misdeed deemed appropriate, and correlatively, what might require their termination?

\section{A. Understating the Problem: The Reductionist Approach}

Some common answers that come readily to mind turn out to be evasions. Especially when in the grip of instrumental rationality, an interest in the future will seem natural and sound, whereas dwelling in the past, idle and irrational. So the temptation is to convert our past-oriented concerns into present or future ones. But by failing to acknowledge our ubiquitous interest in the past qua past, such reductionist accounts do not so much explain reactive attitudes as explain them away. Three putative reasons for our past-oriented attitudes will illustrate the point. The first, and easiest to discard, concerns the enduring results of the assault, such as a broken bone or persisting pain. These results are

1. See P.F. STRAwSON, Freedom and Resentment, in FREEdOM AND RESENTMENT AND OTHER ESSAYS 1-25 (1974), discussed infra text accompanying note 5. The moral significance of resentment is also discussed in Thomas Brudholm \& Valérie Rosoux, The Unforgiving: Reflections on the Resistance to Forgiveness After Atrocity, 72 LAw \& CONTEMP. PROBS. 33 (Spring 2009). 
doubtlessly important, but not quite to the point. Reactive attitudes do not depend on persisting harm and would remain appropriate even in its absence. Moreover, insofar as remedial action plays a role in mollifying resentment, we insist that the action be taken by the offender, not by just anyone. Yet a concern to bring the victim's suffering or loss to an end ought to be indifferent to the source of amelioration.

A second line of thought accounts for the response to the assault in terms of the evidence the assault provides of the wrongdoer's violent character and her disposition toward aggression. Here the past event is said to spell future trouble. ${ }^{2}$ But the emotional response that this line of thought underwrites is not resentment but fear-the same reaction that would be invited by an approaching lion or a flood. Reactions to wrongdoing differ markedly from reactions to danger; the present account effaces this difference. Moreover, reassurance against future danger does not by itself bring the reactive attitudes to an end. For example, the victim may permissibly nurse her grievance even after the aggressive neighbor moves away and thus no longer poses a threat.

A third line of thought characterizes violence, along Kantian lines, as an expression of disrespect, so that the victim's resentment is a protest against ongoing disrespect of the wrongdoer. ${ }^{3}$ But this misrepresents the connection between the victim's resentment and the aggressor's remorse. The attitudes of the wrongdoer and the victim are, of course, related: remorse often paves the road to forgiveness and so to a termination of negative attitudes. Still, it is up to the victim whether to traverse this road and grant forgiveness. This third approach eliminates this choice by making forgiveness automatic or otiose. If the victim's resentment is sustained only by the wrongdoer's ongoing disparagement, then, once this disparagement abates, resentment is deprived of an object; there is nothing left to forgive. ${ }^{4}$

It is possible, of course, to insist on the reductionist approach to pastoriented grievances and to deny the need for an alternative account by simply dismissing people's reactions to the past as unfounded and silly. The bit of human reality at stake here, however, is too pervasive to be so easily dismissed. It makes better sense to treat it not as an aberration but as a challenge. One way of meeting the challenge is implied by the locution "reactive attitudes" that I have been using. This expression originates in an influential paper by Peter

2. See, e.g., Norvin Richards, Forgiveness, 99 ETHICS 77 (1988).

3. This is the gist of Jeffrie Murphy's account of the connection between repentance and forgiveness. Because the repentant wrongdoer is not "now conveying the message that he holds me in contempt," my forgiveness is deemed appropriate: "I forgive him for what he now is." JEFFrIE G. MURPHY \& JEAN HAMPTON, FORGIVENESS AND MERCY 26 (1988).

4. Compare the well-known "paradox of forgiveness" formulated by Aurel Kolnai. Unless forgiveness involves the offender's change of heart, "the wrong is still flourishing, the offence still subsisting: then by 'forgiving' you accept it and thus confirm it and make it worse; or the wrongdoer has suitably annulled and eliminated his offence ... and by 'forgiving' you would only acknowledge the fact that you are no longer its victim. Briefly, forgiveness is either unjustified or pointless." Aurel Kolnai, Forgiveness, 74 PROC. ARISTOTELIAN SOC'Y 91, 98-99 (1973-1974). 
Strawson, in which he explores common responses to wrongdoing such as resentment and guilt. ${ }^{5}$ The core of his account is the observation that reactive attitudes to wrongs cannot be properly understood in purely instrumental terms; rather, they give content or substance to a conception of ourselves as responsible, thereby constituting us as subjects, that is, as the authors of certain objects and events. Although Strawson does not explicitly frame his inquiry in terms of a relationship to the past, his general approach can be easily extended in this direction. By ascribing a certain result to an actor, judgments of responsibility are essentially backward looking. So even the prospective standpoint of practical rationality anticipates the retrospective standpoint of responsibility. To be interested in our future as subjects, individual or collective, is to place special importance on the outcomes of our actions, and to view these outcomes as the earned products of goal-directed efforts, rather than as a fortuitous boon or bane. And this involves anticipating reactive attitudes to our actions such as pride and satisfaction or guilt and remorse, and corresponding reactions, such as admiration and gratitude or resentment and blame, to the actions of others. Eliminating such backward-looking attitudes would accordingly drain the prospective standpoint of action of its essence as the expression of agency. ${ }^{6}$

This is not to deny, of course, that past wrongs often have further present and future ramifications that fan the flame of animosity. Arresting or rectifying such enduring consequences of the wrongful act is obviously of great importance and a necessary step toward the restoration of goodwill. Even so, by ignoring the pervasive interest in the past wrongful act as such, reductionist accounts induce the illusion that these necessary remedial steps are also sufficient, and that reassurance that a past wrong no longer persists and will not recur ought all by itself to allay bad feelings and terminate acrimony. The reductionist misdiagnosis of the problem is thus bound up with a corresponding misunderstanding of the appropriate cure. There is a familiar plethora of responses to wrongdoing: sanction, reparation, apology, pardon, amnesty, repentance, forgiveness, and the like. These practices do undeniably have a prospective aspect in that they address in various ways the present and future ramifications of the wrongful act. But the reductionist tendency focuses exclusively on this prospective aspect, which by itself would leave these

5. See Strawson, supra note 1 .

6. This point is spelled out more fully in Meir Dan-Cohen, Responsibility and the Boundaries of the Self, 105 HARV. L. REV. 959 (1992); a revised version appears in MEIR DAN-COHEN, HARMFUL THOUGHTS: ESSAYS ON LAW, SELF, AND MORALITY 199 (2002). My present focus on responsibility and on reactions to wrongdoing is one aspect of a broader theme that concerns the role that an orientation toward the past plays in constituting both individual and collective subjects. See, e.g., ROBERT N. BELlaH ET AL., HABITS OF THE HEART: INDIVIDUALISM AND COMMITMENT IN AMERICAN LIFE (1985); JEROME BRUNER, ACTS OF MEANING (1990); E.J. Hobsbawm, The Social Function of the Past: Some Questions, 55 PAST AND PRESENT 3 (1972); Steven Knapp, Collective Memory and the Actual Past, RePresentATIONS, Spring 1989, at 123, 134-41; Marya Schechtman, The Truth about Memory, 7 PHIL. PSYCHOL. 14-17 (1994); Eviatar Zerubavel, Social Memories: Steps to a Sociology of the Past, 19 QUAL. SOCIOL. 283 (1996). 
practices utterly ineffectual in dealing with the distinctly past-oriented dimension of reactive attitudes.

\section{B. Overstating the Problem: Fixation on the Fixity of the Past}

Though the reductionist approach to past-oriented grievances is pervasive, it is not the only one. Two rather radical suggestions for escaping the past's shadow, one I call ontological and the other epistemological, do meet the problem of the past head on. Upon further inspection, however, both suggestions appear to be counsels of despair, since the conditions they set on reconciliation or the measures they recommend to attain it are too extreme.

"Ontological" refers here to a concern with the continued existence or identity of the contending parties. The basic idea is simple and stark. To revert to the example of the neighbors, if either of them were to die, acrimony would come to an abrupt, if tragic, end. Though this would resolve the conflict only in a Pickwickian sense, this scenario does in fact provide a model for a serious theme.' Reactive attitudes are relational, addressed for the most part by a victim to a wrongdoer, ${ }^{8}$ and so require that both parties continue to exist. Because states and other collectivities do not typically cease to exist by death in the literal sense, the discussion tends to focus on their conditions of identityfor example, is today's Russia continuous with Tsarist Russia, or today's France with Napoleon's? The assumption animating such inquiries is the same as that concerning the neighbor's death. Unless the country that had perpetrated a wrong still exists, those wronged have no addressee for their complaint.

But, as the analogous case of the neighbor's death also teaches, such appeals to discontinuous identity are not a promising track. First, an interest in reconciliation arises only among parties who at least view themselves as respectively continuous with the wrongdoer and the victim. To take seriously the notion that one or both parties to a dispute is no longer around is not to effect a reconciliation but to deny the need for it. Second, the conclusion that the wrongdoer no longer exists achieves the abatement of grievances at the victims' expense, as it deprives them of any recourse and nullifies wholesale all claims to remedial steps. Third, and most important, discontinued identity is a binary, all-or-nothing notion. As such it is ill-fitting with the temporal career of many collectivities. Ordinarily, we do not expect questions regarding the continuity of Russia or France to have clear yes-or-no answers. A theory-driven attempt to provide such an answer is likely to be artificial and unconvincing, a shaky foundation for the desired changed attitudes.

7. For a critical discussion of the change-of-identity approach in the case of individual wrongdoing, see JORAM GRAF HABER, ForgIVENESS 95-98 (1991); Joanna North, Wrongdoing and Forgiveness, 62 PHIL. 499 (1987). Ruti Teitel discusses decisions regarding reparations for past wrongdoing by a previous regime as involving a dialectic of continuity or discontinuity of identity. RUTI TeITEL, TRAnsitional JUSTICE 137, 146-47 (2000); for a more general discussion of states' conditions of identity as they bear on responsibility for past wrongs, see id. at 192-93.

8. To simplify matters, I ignore here the offender's own reactive attitudes such as guilt. 
The epistemological response to the problem of the past is based on the realization that for past events to cast a shadow, we must be aware of them. So the suggestion is sometimes made that relief from the burdens of the past lies in forgetting; amnesia is allegedly a strategy societies can use to escape an unpleasant past.' This response is no more attractive than the ontological. One reason is unreliability: deliberate attempts at forgetting are notoriously counterproductive ("don't think about an elephant") and precarious, easily reversible by anyone who cares to provide a reminder. More importantly, knowledge of the past, and in particular of a grim past, is a valuable source of learning that can help avoid repeating past abominations and mistakes. Foregoing this knowledge is a high price to pay even for attaining a desirable goal.

But why are such radical responses to the problem of the past deemed necessary? Why invoke the equivalents of death and amnesia to escape the past's shadow? In contrast to the reductionist approach, which evades the problem of the past and thus understates its difficulty, these responses tend to overstate the problem and thus overreact. The source of the overstatement and overreaction lies in a simple oversight. We tend to focus on the past, which indeed is unalterable..$^{10}$ But when it comes to wrongdoings and grievances, we are not in fact interested in the past as such. Reactive attitudes to past wrongs are addressed not to the wrongs themselves, abstractly conceived, but to their perpetrators: the concern in all such cases is with someone's past. And to speak of someone's past is to speak of a relationship, namely, that between some events and a subject. The belief that the past is unchangeable pertains only to one of these two: the events themselves. This does not preclude the possibility that the subject might change, particularly in such a way as to no longer be the subject of these events. The inquiry accordingly shifts away from a fixation with the past itself and from the hopeless task of undoing or modifying it. We need to focus instead on the subjects of the wrongful acts and to rephrase the

9. Those observing this way of escaping the past often lament it: "[T]he worst distortion is willed amnesia, whether for the sake of self-exculpation or some sort of convenient reconciliation." Fritz Stern, N.Y. TIMES, May 12, 1985 (reviewing Eberhard JAECKEL, HITLER IN HiSTORY (1985)), quoted in DONALD W. SHRIVER, JR., AN ETHIC FOR ENEMIES: FORGIVENESS IN POLITICS 103 (1995). Teitel speaks of the amnesty granted in Spain to members of the Franco regime as "an agreement to forget the distant past." TEITEL, supra note 7, at 53; see also NORMAN M. KLEIN, THE HISTORY OF ForgetTING: LoS ANGEles AND THE ERASURE OF MEMORY (1997); AVISHAI MARGaLIT, THE ETHICS OF MEMORY 205 (2002) ("Total forgiveness entails forgetting."); Robert B.J. Walker, Sovereign Identities and the Politics of Forgetting, 9 PUBLIC 95 (1994).

10. The theme of the past as a heavy weight and of the yearning to shake free of it is captured well in Hannah ARendt, The Human Condition 33 (1958). See also Theodor W. Adorno, What Does Coming to Terms with the Past Mean?, reprinted in BITBURG IN MORAL AND POLITICAL PERSPECTIVE 115 (Geoffrey H. Hartman ed., 1986) ("One wants to get free of the past: rightly so, since one cannot live in its shadow, and since there is no end to terror if guilt and violence are only repaid, again and again, with guilt and violence."). Adorno talks about the "destruction of memory" as responding to this desire, and associates it with the devil's position in Goethe's Faust. Id. at 117. Others underscore the futility of attempts to escape the past: "[R]epentance consists in our setting ourselves against a past reality and absurdly attempting to efface that reality from the world." Haber, supra note 7, at 94. 
relevant question: how are we to understand the temporal career of collective entities such as states, and how does this career affect their relationship to past events?

\section{III \\ TEMPORAL BOUNDARIES AND THEIR CHANGE}

The answer I propose is based on an analogy between a state's spatial and temporal dimensions. It is a commonplace that a state's geographic border can be changed and that such a change affects the state's responsibility. Analogous shifts in a state's temporal boundary are also possible, bearing a similar relationship to responsibility and consequently to the appropriate responses to a past wrong.

\section{A. Spatial and Temporal Boundaries}

Consider a simple example of a territorial change. The state of Arcadia has within its border a pollutant that causes environmental damage. As a matter of course, Arcadia bears responsibility for this pollutant: it is required to take measures to reduce the damage, to compensate affected parties, and the like. It is equally obvious that this responsibility would expire if, say, by treaty or war, Arcadia's border were redrawn so as to exclude the offensive site."

Five features of this example are noteworthy. First, the example illustrates how a border change can affect responsibility by removing a responsibility base. Second, it makes vivid the constructive and hence indispensable role played by the process or action by which the boundary is changed. Many good reasons for retracting Arcadia's border may have existed prior to the change, and these reasons may have prompted the actions, peaceful or belligerent, for making the change. But the reasons themselves, no matter how compelling, are not selfexecuting. Arcadia's responsibility for the pollutant would persist in face of such reasons until and unless the change in the border is actually made. How might a treaty or war be agents of such a change? Since the change would be normative, the answer must also be normative: certain events and certain parties have the normative power to affect a state's boundary in the sense that the occurrence of these events or actions taken by these parties simply mean or count as a border change. ${ }^{12}$ Why do they mean this, or to whom do they so count? What are the source and the scope of this power?

11. In light of the analogy to temporal boundaries that I wish to draw, two clarifications of this example are in order. First, the border change does not relieve Arcadia of obligations that accrued before the change. The point is only that pursuant to the change, no new obligations will accrue. Second, it is immaterial whether after Arcadia's border changes, the pollutant is joined to another state or winds up in some unowned territory. The latter possibility is less likely on a globe that is mostly divided among states, but this is a contingent, and indeed a relatively recent, situation.

12. On the significance of "counting as" as fundamental to social phenomena in general, see JOHN R. SEARLE, THE CONSTRUCTION OF SOCIAL REALITY 43-51 (1995). 
The third feature is that neither logic nor political practice mandates that these questions have a clear and uniform answer. There is room among states not just for border disputes but also for disputes about the proper means of settling them, without there being a supreme authority able to resolve all such disagreements. There is accordingly room for indeterminacy in the location of a state's border, with different parties accepting different territorial versions of the same state. Fourth, note the delicate balance between continuity and change in the Arcadia scenario. To say that Arcadia's boundary has been redrawn implies a change substantial enough to relieve Arcadia of responsibility but not so substantial as to threaten the state's continued identity. Though the region containing the pollutant is no longer part of Arcadia, the state of Arcadia does persist as a viable subject, so saying that $i t$ is no longer responsible for the pollutant is not an empty or a paradoxical claim. Finally, Arcadia's territorial parts, either before or after the border change, need not be contiguous. Lack of contiguity does not render Hawaii and Alaska any less parts of the United States than is, say, Nebraska.

The pollutant is an object, so a geographic border change is adequate to the task of removing it from the scope of Arcadia's responsibility. Our interest, however, is not in objects but in events. Instead of the pollutant, consider a past mischief committed by Arcadia against a neighboring state. Imagine that some time ago Arcadia invaded Tasmania, wreaking havoc on its people. After a heroic struggle, the Tasmanians managed to evict the invaders and regain their freedom. But emotions in Tasmania have since run high; hostility toward Arcadia persists, and occasional calls for retaliatory action are made. These reactive attitudes are the incidents of holding Arcadia responsible for the mischievous acts. To render these attitudes no longer appropriate and bring them to an end would accordingly require that Arcadia be relieved of that responsibility. In the case of the pollutant, redrawing Arcadia's territorial boundary would accomplish such a feat. Can we analogously think of redrawing Arcadia's temporal boundary so as to exclude the invasion? My suggestion is that such common responses to wrongdoing as sanctions, reparations, apologies, and the like, do just that. These responses are best understood as, in part, "revisionary practices"-devices for redrawing a state's temporal boundary so as to exclude a past event. Consequently, the five features highlighted in the pollutant case apply in the temporal case as well.

First and most importantly, by redrawing the wrongdoer's temporal boundary, revisionary practices relieve the wrongdoer of responsibility for the wrongful act. In doing so, these practices render reactive attitudes, the ordinary incidents of responsibility, no longer appropriate. Second, these practices are constructive in the sense that the effects on the wrongdoer's boundary and responsibility are brought about by the practices themselves, cumulatively or in some combination, rather than by any antecedent reasons for activating them. This explains the normative significance of these practices over and beyond their material and psychological effects. By engaging in revisionary practices, various parties exercise normative powers to modify the wrongdoer's boundary. 
Where do these powers come from, and how do they relate to each other? Though roughly speaking the answer must rest on various parties' special interests in the wrongful act, the third feature of the territorial analogy teaches that these powers are contestable and vague, so the resulting boundary line may be indeterminate and ill-defined. Consequently, the connection between different revisionary practices is contingent and loose: they may, but need not, be activated in harmony and converge. As in the territorial case, in the temporal case different versions of the same state may coexist. ${ }^{13}$

An advantage of this account is that it insists on the practices' logical independence while highlighting their interconnectedness. Though disparate drawings of a boundary are possible, at least three factors exert considerable pressure for convergence. One factor consists of the reasons that trigger any of the various practices. Since these are reasons for redrawing the wrongdoer's boundary in a particular way, the reasons that prompt one of the revisionary practices are likely to invite the other practices as well. The second factor concerns the relationship among the practices. Some revisionary practices provide reasons for others. For example, though a wrongdoer's remorse does not necessitate forgiveness, it does provide a strong reason for it. Third, the advantages of uniformity and agreement regarding the location of the boundary line encourage recognizing or ratifying a boundary simply because a party putatively empowered to do so has drawn the boundary in a particular way.

The fourth feature of the territorial case illuminates the kind of change in the wrongdoer that the revisionary practices involve. Like redrawing a state's boundary to exclude a chunk of land, excluding certain events from the ambit of a state's temporal boundary is a change significant enough to support and explain the cessation of negative attitudes toward the offending state, though not so extensive as to disrupt the state's identity. Finally, lack of contiguity in the territorial case corresponds to lack of continuity in the temporal case. Discontinuous events can be unified to form a state's past just as disconnected territories can form its geography. Conversely, just as dislodging a bit of land by a territorial border change might leave a gap, so might dislodging some events by changing the temporal boundary. ${ }^{14}$

\section{B. Toward an Ontology of the State}

An analogy between a change in a state's temporal boundary and a territorial change provides a way of addressing not just the present and future concerns raised by a wrongful act, but the distinctly past-oriented concerns as

13. This indeterminacy in subjects' temporal shape should be distinguished from Ian Hacking's well-known and controversial view that, because emerging new concepts issue in novel descriptions of past events, there is an indeterminacy regarding the past. See IAN HACKING, An Indeterminacy in the Past, in REWRITING THE SOUL: MULTIPLE PERSONALITIES AND THE SCIENCES OF MEMORY 234-57 (1995).

14. For a sensitive discussion of such temporal gaps seen as analogous to a "no man's land" situation in the spatial domain, see TEITEL, supra note 7, at $69,77,183$. 
well. But how can a change in a state's territorial shape possibly illuminate our dealings with its past? Is there not a fundamental difference between time and space with respect to change? Excluding the pollutant from Arcadia's geographic scope is easy; but isn't this quite unlike excluding a wrongful act from Arcadia's temporal scope? The challenge these questions pose looks especially compelling when seen against a particular backdrop-namely, an implicit picture of states as ordinary material objects. In this picture, the geographic borders of states resemble those of other objects that occupy a volume of space or cover some region of the earth. To be sure, such material objects do come into being and eventually expire and in this sense can be said to have temporal boundaries - a beginning and an end. But this notion of boundary is quite unlike the spatial one. The main difference concerns change. Much of the significance that attaches to territorial borders comes from the possibility of redrawing them. Shifts, actual or potential, in states' geographic composition are a central preoccupation of the international political scene. No similar latitude seems available in the temporal dimension, rendering the notion of a temporal boundary understood as marking the fixed points of inception and termination relatively sterile and superfluous.

The picture of the state as a material object resonates with us, and its spatiotemporal implications are often taken for granted. But a moment's reflection ought to stir us from such metaphysical slumber. ${ }^{15}$ Are states really equivalent, ontologically speaking, to sticks and stones? Giving up this imagery, and attending instead to the state's true ontological status, reveals that the state's spatial dimension is actually quite analogous to its temporal dimension. Changes in both types of boundaries thus turn out to be feasible and to have corresponding normative effects. To see this we need to consider more carefully the case of a territorial change. At first glance, the spatial features of this change appear obvious. Arcadia has indeed been cut down and reduced in size; its territory has shrunk. The alteration thus appears to resemble what happens when a tree is trimmed or a rock chiseled. But the appearance is misleading. Reducing the size of a tree or a rock does consist in these physical operationsthe trimming or the chiseling-and their resulting material reconfigurations. Reducing Arcadia's size, by contrast, involves no such physical operations and no material change. Everything on the ground remains just as it was.

15. Others have warned against the tendency to reify states' territorial borders, for example, by pointing out that "[territoriality] simplifies issues of control and provides easily understood symbolic markers 'on the ground,' giving relationships of power a greater tangibility and appearance of permanence." James Anderson \& Liam O'Dowd, Borders, Border Regions and Territoriality: Contradictory Meanings, Changing Significance, 33 Regional STUD. 593, 598 (1999). See generally BENEDICT ANDERSON, IMAGINED COMMUNITIES (revised ed. 1991) (1983). Even so, there is a surprising dearth of serious philosophical reflection on the territoriality of states. As a recent commentator testifies, "[C]ontemporary political philosophers, like their historical predecessors, have almost always begun with the idea of states as units with legitimate territorial dimensions, proceeding more or less immediately to questions about how such territorial states can be justly governed." A. John Simmons, On the Territorial Rights of States, 11 PHIL. ISSUES 300, 302 (2001). 
Specifically, the pollutant does not change its location, and its emissions continue to affect the same region as before. What then does the change of boundary consist of? How does it exempt Arcadia from responsibility?

In order to answer these questions, we must pose a more basic one: why is Arcadia held responsible for the pollutant in the first place? The common reply would simply point out that the pollutant is on Arcadian soil. Though this reply is valid and plays an indispensable pragmatic role in ordinary dealings with these kinds of issues, it hides more than it reveals. At a deeper explanatory level, a more informative answer is available. Rather than a state's being responsible for $X$ because $X$ is within its boundaries, it is the other way round: $X$ is said to be within the state's boundary insofar as and in the sense that that state bears responsibility for it. To say the pollutant is in Arcadia is not to specify its geographic location in the same sense as pointing out that it is, say, a hundred miles south of the Rockies. It is instead to indicate a normative, jurisdictional property, one that alludes to a complicated network of institutional and other normative arrangements that can be summarized, if somewhat crudely, by the statement that Arcadia is responsible for that pollutant. The answer to the question about what a boundary change is and to the question about how it releases Arcadia from responsibility is, therefore, one and the same: a border change ultimately just is a reallocation of responsibility.

How are we to reconcile these two replies-the common, pragmatic one, which views the pollutant's location within Arcadia's borders as the grounds for Arcadia's responsibility, and the theoretical, explanatory one, which reverses this statement? Correspondingly, how can a reallocation of responsibility over the pollutant be explained by a border change when border changes just are reallocations of responsibility? To see the gist of the matter, consider a variant on the original example. Imagine that in Arcadia's case the usual incidents of the border line do not converge on a single geographic location: some people are allowed to enter Arcadia's territory at one putative "entry point" while others may enter elsewhere; customs are paid at some points but not others; Arcadia bears only partial responsibility for certain goings-on in some scattered territories, whereas others are responsible for the remaining goings-on and the remaining regions; and so on. Obviously, at some point such arrangements would drain talk of a border of all meaning, and any talk of Arcadia would be empty too. The impracticality of this alternative arrangement, at least in the world as we know or think we know it, is also apparent. This impracticality serves as a backdrop for understanding the pragmatic role of reifying border and state. Though a state's border is but the reflection of such normative arrangements as I have mentioned, the border provides various norms with a focal point, thus allowing for an easy consolidation of what would otherwise be cognitively and practically an unwieldy jumble of such norms. Correspondingly, border-changing practices such as treaties are devices for inducing in one fell swoop the modification of an entire battery of norms and attitudes considered to be the common incidents of the border's location-a modification that in principle, but probably not in actuality, could be wrought piecemeal, without 
recourse to the orienting or unifying idea of a border and its change. So, to cite the location of or change in a border as the grounds for judgments of responsibility is simply to take advantage of the orientation and unification that the idea of border provides.

I have mostly stressed the relationship of borders and their changes to the allocation of responsibility, but actually more is often at stake. Other factors, such as various people's attitudes and attachments regarding the territory in question, are significant too. Still, taking account of these additional factors, though doubtlessly complicating matters, does not affect the main point. To see the point more clearly, we need to distinguish between two senses of spatial: "in space" and "pertaining to space." Trimming trees and chiseling rocks are spatial in the first sense, since they involve essentially the redistribution of matter in space. Redrawing a country's boundary, by contrast, is spatial in the second sense; it is changing the network of normative relations, as well as other understandings and attitudes, pertaining to a particular piece of land. Now a similar distinction also applies to temporal. In one sense a temporal change would require an alteration in the sequence of events. It is a fundamental tenet of commonsense metaphysics that, unlike the corresponding spatial changes, temporal changes of this kind are impossible. A second sense of temporal, however, is that of "pertaining to" or "concerning" time. Changes in the significance we attach to past events, in our attitudes toward them, and most important, in their normative ramifications, are temporal in this second, innocuous sense. ${ }^{16}$

We can now identify with precision the faulty premise of the objection to the analogy between a temporal and a geographic change. The objection implicitly views the spatial border change, and correspondingly the temporal change wrought by revisionary practices, as involving the first sense of the respective adjectives, whereas they actually involve the second sense. The bearing this has on the argument must by now be clear. Just as redrawing Arcadia's territorial border does not require any rearrangement of material objects but consists instead in a reduction in the spatial scope or field of

16. Though the present focus is on the temporal dimension of the state, ignoring the two senses of both spatial and temporal has deleterious effects on the treatment of spatial conflict as well. Consider, for example, John Urry's claim that temporal and spatial relation "are asymmetrical. In particular, relations within space must exhibit a constant sum, while relations within time are not so constrained. ... Hence, space is necessarily limited and there has to be competition and conflict over its organisation and control." John Urry, Social Relations, Space and Time, in SOCIAL RELATIONS AND SPATIAL STRUCTURES 20, 30 (Derek Gregory \& John Urry eds., 1985). To see the problem with this view, imagine a conflict between two neighboring states as to whose capital a particular city near the border should be. This would seem to present the kind of zero-sum spatial conflict manifesting the scarcity of space that Urry has in mind. But this conceptualization of the matter misrepresents the possibilities. In addition to the two exclusive, either-or solutions to the conflict, a third solution exists, namely that this city serve as capital of both countries. This option can take the form of indeterminacy-different parties consider the contested city as the capital of one state or the other, without further resolution. Or, better yet, normative arrangements can make the city count as the capital of both contending states. 
application of some norms and attitudes, specifically with regard to the pollutant, so in redrawing its temporal boundaries, revisionary practices need not interfere with the sequence of events. All the practices need accomplish is a contraction in the temporal scope or field of application of some norms and attitudes, specifically regarding the invasion of neighboring Tasmania. In the spatial case, changes in norms and attitudes regarding the pollutant effectively relieve Arcadia of responsibility for it. Similarly, changes in norms and attitudes regarding the invasion can render Arcadia no longer responsible for it either.

The imagery of boundaries captures both of these situations. In the one case, involving an object, we express the change by saying that the object is now outside the state's territorial boundary; in the other case, involving an event, we can say in a similar vein that the event is outside the state's temporal boundary. When revisionary practices have run their course-after sanctions are imposed, reparations and apologies made, and forgiveness granted-a change in Arcadia's temporal border, one excluding the past misdeed, comes into effect. In contrast to the radical ontological response to the problem of the past, such a change does not amount to a switch in identity that implies Arcadia's ceasing to exist. Rather, this change only signals the release of Arcadia from responsibility for the invasion. Consequently, the reactive attitudes toward Arcadia based on that invasion are no longer appropriate and must come to an end.

\section{IV}

\section{FROM MEMORY TO HISTORY}

The preceding modification of the ontological response to the problem of the past has a corollary on the epistemological level as well. As commonly understood, escaping the shadow of the past by forgetting carries with it the seemingly unavoidable price of forfeiting knowledge of the past event. But the notion of a change in temporal boundary offers an intermediate possibility here too. This possibility is bound up with a distinction that has come to occupy center stage within scholarly fields dedicated to the study of the past. In the last quarter century or so, this study has greatly diversified its interests and methodology to the point that the traditional designation "historian" no longer fits all practitioners. Part of this diversity came to be marked by a salient if highly contested opposition between history and memory, with scholars proclaiming themselves, sometimes vehemently, as studying the one or the other. ${ }^{17}$ My point, in a nutshell, is that if history and memory mark two different

17. For a sample of the large literature, see PATRICK H. HutTon, History AS AN ART OF MEMORY (1993); Pierre Nora, General Introduction: Between Memory and History, in 1 REALMS OF MEMORY: RETHINKING THE FRENCH PAST (Lawrence Kritzman ed., 1996); Noa Gedi \& Yigal Elam, Collective Memory-What Is It?, 8 HIST. \& MEMORY 30 (1996); Wulf Kansteiner, Finding Meaning in Memory: A Methodological Critique of Collective Memory Studies, 41 HIST. \& THEORY 179 (2002); Kerwin Lee Klein, On the Emergence of Memory in Historical Discourse, REPRESENTATIONS, Winter 2000, at 127; Thomas W. Laqueur, Introduction, REPRESENTATIONS, Winter 2000, at 1; Allan Megill, History, Memory, Identity, 11 HIST. OF THE Human SCI., Aug. 1998, at 37; Jeffrey K. Olick \& Joyce 
epistemological positions, two modalities of knowing the past, then there are likely to be two different ways of negating them as well. Juxtaposing history to memory accordingly reveals a logical space for a relationship to the past that otherwise goes unnoticed. Retaining or losing historical knowledge is one thing; remembering or forgetting a past event is another. It should be possible to cease remembering an event while retaining historical knowledge of it. A change in temporal boundaries allows us to occupy this middle ground.

Two preliminary clarifications of my use of the terms history and memory are in order.$^{18}$ First, the past events referred to by both terms as I use them are for the most part collective in nature. This is more obviously in keeping with common usage in regard to history than to memory, the latter being more commonly associated with individuals' biographical events. However, the juxtaposition of memory to history in the study of the past crucially involves the idea of collective memory, the extension of the notion of memory to a collectivity's relationship to its past. ${ }^{19}$ So understood, memory is not distinguishable from history in subject matter along the individual-collectivity line; the very same events can serve as the subject matter of both. Second, according to common usage, labeling a representation as either history or memory does not necessarily include a warranty of reliability: history can be fabricated, and memory false. Talk about fabricated history or false memory, however, plainly uses the respective terms in a degenerate and derivative sense, a sense rendered with greater clarity by appending some qualifier such as "pseudo" to them. In their primary signification both history and memory are veridical. In this sense, both history and memory involve knowledge of past events. ${ }^{20}$

Robbins, Social Memory Studies: From "Collective Memory" to the Historical Sociology of Mnemonic Practices, 24 ANN. Rev. SoC. 105 (1998).

18. The distinction between these terms is as contested as it is salient. As one scholar observes, "The appearances of the word [memory] are so numerous, and its apparent meanings so legion, that it would take the work of a lifetime to begin disentangling them." Klein, supra note 17, at 129. I highlight those aspects of the juxtaposition that best suit my line of argument.

19. The classical text that introduced the notion of collective memory is MAURICE HALBWACHS, ON COLlective Memory (Lewis Coser ed. \& trans., Univ. of Chicago Press 1992) (1941). For some general discussions of the issues involved see, for example, COLLECTIVE REMEMBERING (David Middleton \& Derek Edwards eds., 1990); PAUl ConnerTON, How SOCIETIES ReMEMBer (1989); IWONA IRWIN-ZARECKA, FRAMES OF REMEMBRANCE: THE DYNAMICS OF COLLECTIVE MEMORY (1994); Susan A. Crane, Writing the Individual Back into Collective Memory, 102 AM. HIST. REV. 1372 (1997); Jeffrey K. Olick, Collective Memory: The Two Cultures, 17 SOC. THEORY 333 (1999) (juxtaposing what he calls "collected memory," which is an aggregate of individual memories, to genuinely "collective memory," tied to national narrative and identity); as well as sources cited in supra note 17.

20. Cf. Paul Ricoeur, Memory and Forgetting, in QUESTIONING ETHICS: CONTEMPORARY DeBATES IN PhILOSOPHY 5, 5 (Richard Kearney \& Mark Dooley eds., 1999) ("Memory constitutes a knowledge of past events, or of the pastness of past events. In that sense it is committed to truth, even if it is not a truthful relationship to the past; that is, precisely because it has a truth-claim, memory can be accused of being unfaithful to this claim."). 
But if both memory and history consist in knowing the very same facts, wherein does the difference lie? To answer this question we must raise other ones. Why has memory assumed such a dominant role in our dealings with the past, in part supplementing, in part supplanting what hitherto has been treated as history? Why has the juxtaposition of memory to history become so contested, and what is at stake in this debate? The answer to the latter questions, which also provides a clue to the earlier one, concerns the special significance that attaches to memory as a source or form of knowledge of the past. At least since Locke, memory has been widely regarded as a criterion of personal identity. ${ }^{21}$ To a large degree, talk of collective memory has assumed its significance by extending this Lockean approach from individuals to collectivities. ${ }^{22}$ To follow this step, however, requires a closer look at the connection of memory to identity in the individual case.

Consider a biographical event, such as Sarah's climbing Kilimanjaro as a child. Years later she speaks about this experience to a friend. In doing so, Sarah may be recounting her memory of the climb; alternatively, she may by now have entirely forgotten the climb, instead basing her report on the evidence of some old photographs that bear her name. Three related differences between these two scenarios are noteworthy. First, in the latter case, Sarah's report and the knowledge it conveys stand in the same relationship to the climb as anyone else's might. By viewing the photos or consulting some other reliable bit of evidence, anyone could acquire the information in the same way Sarah has. In the former case, by contrast, Sarah's knowledge is based directly on her having climbed the mountain; it links her to that action in a distinctive way that is unavailable to anyone else. ${ }^{23}$ We can mark this difference by saying that memory involves internal knowledge of the climb, unlike the external knowledge involved in the second scenario. Characteristically-and this is the second point-memory involves affective knowledge as well. To remember a climb is to remember it as arduous or exhausting or exhilarating or fun. Particularly significant here are emotions such as pride or shame that can be entertained only by the agent herself.

That the knowledge memory involves is internal and affective reflects a third and more fundamental difference between the two scenarios. In the second scenario, Sarah's report is prone to a kind of mistake to which her

21. The classical statement of his position is in JOHN LOCKE, AN ESSAY CONCERNING HUMAN UNDERSTANDING ch. 27 (A.D. Woozley ed., 1974) (1670). Whether or in what precise sense Locke held that memory is a criterion of personal identity is a matter of some contestation. See, e.g., MARYA SCHECHTMAN, THE CONSTITUTION OF SELVES 27-30 (1996).

22. The connection between memory and identity is a dominant theme in the collective memory literature. As Kerwin Lee Klein puts it, "The two words ['memory' and 'identity'] are typically yoked together; to mention the one is to mention the other." Klein supra note 17, at 143-44.

23. This is a reflection of what has been called the "previous awareness condition" of memory. Sydney Shoemaker, Persons and Their Pasts, 7 AM. PHIL. Q. 269, 269 (1970). Of course, others may have seen her climb, and so remember that event too. But strictly speaking, what they remember is their own experience of seeing Sarah climb. 
memory is not: misidentifying the climber. Though the named photograph may provide reliable evidence that the pictured girl named Sarah had climbed Kilimanjaro, this does not preclude the possibility that a different Sarah had been involved. The Sarah who is reporting the event on the basis of such evidence is as liable as anyone else to mistake the climber's identity. Consequently, an epistemically scrupulous Sarah might render the evidence provided by the photograph by using a third-person locution, to the effect that "Sarah climbed Kilimanjaro," or, pointing at the girl depicted, "she climbed," thereby marking the logical gap between the evidence adduced and the conclusion that the climber and the reporter are one and the same person. Memory, by contrast, leaves no such gap and so is immune to mistaken identity. Memory enables or licenses the conversion of a present-tense, self-referential statement that Sarah might have made at the time of the climb, "I'm climbing Kilimanjaro," into the past-tense, self-referential statement, "I climbed Kilimanjaro." In this case, the matter of the climber's identity is conceptually sealed. A memory is accordingly more than just a source of information about the actions it recalls; the very possession of that bit of information qua memory manifests the temporal continuity and hence identity between the subject of that action and the reporter. To report a memory of climbing is ipso facto to reveal oneself as the subject of that climb. ${ }^{24}$

This feature of memory, call it reflexivity, is why John Locke considered memory a key to personal identity, the glue that holds together the time-slices that constitute a self..$^{25}$ On further reflection, however, the situation has proven to be more complicated; the glue is far from perfect, albeit not so imperfect as to render it useless. A valid memory claim does indeed indicate a direct, internal link between the reporter and the action she remembers. And for the most part we do take the validity of memory claims for granted. But when a memory claim is contested and doubt cast on the reporter's identity as the subject of the events purportedly recalled, one cannot appeal to the memory itself to settle the issue; some other criterion of identity must be invoked. The relationship between memory and identity is accordingly a two-way street. Remembering an action guarantees that the actor and the reporter are one and the same. But a report qualifies as memory only if we either take for granted or are satisfied on other grounds of the subject's identity. ${ }^{26}$

24. Cf. Shoemaker, supra note 23 , at 270 ("[W]here the present tense version of a judgment is immune to error through misidentification relative to the first person pronouns contained in it, this immunity is preserved in memory.").

25. See supra note 21.

26. The contention that a memory criterion of personal identity would be circular since memory presupposes personal identity was introduced in Joseph Butler, Of Personal Identity (1736), reprinted in PERSONAL IDENTITY 99-105 (John Perry ed., 1975). For some of the main steps in the debate that ensued, see Harold NoONAN, Personal IDENTITY (1989); DEREK PARFIT, REASONS AND PERSONS 219-28 (1986); David Lewis, Survival and Identity, in THE IDENTITIES OF PERSONS 17-40 (Amélie Oksenberg Rorty ed., 1976); John Perry, Personal Identity, Memory, and the Problem of Circularity, in PERSONAL IDENTITY, supra at 135-55; Shoemaker, supra note 23; Marc Slors, Personal 
Though the connection of memory to identity was initially forged in the case of individuals, our present interest is in the extension of this connection to collectivities. Talk of collective memory is part of an intellectual swell that effaces at least to some degree the distinction between individuals and collectivities, maintaining, inter alia, that individual identity is in part a matter of social roles and affiliations..$^{27}$ Our goal is accordingly to extend to collective memory the lessons gleaned from the individual context. To do so, in place of Sarah's mountain climbing, consider a historical event analogous to the imaginary conflict between Arcadia and Tasmania-the British victory over France at Waterloo. What would a collective memory of such an event amount to? How and by whom can a nineteenth-century war be remembered today?

Rephrasing these questions helps to answer them. The transition from individual to collective memory is marked by a shift in pronoun. In Sarah's case we distinguished her first-person memory report, "I climbed Kilimanjaro," from a third-person version based on external evidence. The corresponding collective-memory statement would naturally take the form "we won the battle of Waterloo," which can be juxtaposed to a third-person version, stating that "the British won." Accordingly, the inquiry can be restated as focusing on who may permissibly use the we locution in reference to this past event and on the special significance that attaches to this usage when construed as an expression of collective memory.

In transposing memory from the individual to the collective context, the two aspects of memory, knowledge and reflexivity, must be given a suitable gloss. First, note what is not at issue: the British victory itself. Crucially, in exploring epistemological relations to a past event, we take the event itself as given. Specifically, we accept talk of "Britain" and of "winning" as permissible references to a collective subject and its action. Winning a battle, however, involves innumerable actions by individuals, with each action consisting of some bodily movement and an intention or other state of mind. When speaking about "Britain's victory," we ascribe to the collective subject a single, intentional action that supervenes on the individual actions. A great deal of social theory is an effort to spell out what this relation of supervenience amounts to, and much disagreement persists. However, collective knowledge of the past raises no new issue in this regard. Ascribing to Britain the collective memory of the victory can proceed on the same basis, whatever precisely it may be, as that on which the victory itself is ascribed to Britain in the first place.

Nor does the reflexivity of memory raise any issues not already involved in the past action itself. The self-referential, present-tense statement, "We are winning this battle," could have been appropriately made not just by

Identity, Memory, and Circularity: An Alternative for Q-memory, 98 J. PHIL 186 (2001); E. M. Zemach, Memory: What It Is, and What It Cannot Possibly Be, 44 PHIL. \& PHenomenological Res. 31 (1983).

27. For a survey of the issues and the literature concerning the relationship of individuals and collectivities raised by the notion of collective memory, see, for example, the section Between Individual and Collective in Kansteiner, supra note 17, at 185-90. 
Wellington, his generals, or any of the foot soldiers, but by any contemporaneous Brit. By virtue of what? Simply by virtue of being British, that is, being identified with the same collective subject to which the victory is ascribed. And given that this identification underwrites the appropriate "we" statement in the first place, no special puzzle arises regarding its possible use by British people today. The longer temporal horizon need not undo the reflexivity involved. Britain persists over time, so identification with it would give a present-day Brit a basis for using a past-tense reflexive locution regarding the battle, similar to the basis that was available to the battle's British contemporaries for making the corresponding present-tense statement. Moreover, the contemporaries' identification with Britain evinced by firstperson-plural locutions is likely to be bound up with some personalized emotions, such as pride or shame. These emotions can also be perpetuated by the reflexivity of collective memory, and conveyed by a present-day Brit via a "we" reference to the battle. ${ }^{28}$

This account of collective memory parallels the account of individual memory as illustrated by Sarah's case. But this is only half the story. The other half is that all this may, but need not, be the case. Once more, the crucial reminder is that Britain is not a natural-kind term, and its persistence is not that of a material object. To speak of Britain as a unified subject is to take seriously some propositions regarding certain geographic regions and certain events. It is, for example, to accept that, say, Lake Windermere is in Britain. And, by the same token, it is to recognize certain goings-on in the nineteenth century as Britain's doings. And as I have argued in the previous section, such propositions are founded on a cluster of norms and attitudes that range over people, territories, and events. But precisely which people, territories, and events depends on the content of the norms and attitudes and is thus variable, indeterminate, and contested. Consequently, the Britain that plays a constitutive role in forming a contemporary Brit's identity need not include the victory over Napoleon. This can be visualized as a change in Britain's temporal boundary, one that leaves the war with Napoleon outside. Likewise relevant here is the analogy between lack of contiguity in a state's territorial shape and discontinuities in its temporal shape. States can be selective though not arbitrary regarding the events that make up their past, just as they can be regarding territories they inhabit. ${ }^{29}$

28. On the connection between collective memory and such emotions as pride and shame, see, for example, Zerubavel, supra note 6, at 290.

29. On this view, collective memory is a legitimate field of political contestation in a way that history is not. This is congruent with the spirit of Foucault's warning that "Since memory is actually a very important factor in struggle ... , if one controls people's memory, one controls their dynamism." Michel Foucault, Language, Counter-Memory, Practice: Selected Essays and INTERVIEwS (Donald F. Bouchard ed. \& trans., Sherry Simon trans., 1977), quoted in Olick \& Robbins, supra note 17, at 126. Eviatar Zerubavel talks in this context of the "[f]ierce mnemonic battles [that] are ... fought over what ought to be collectively remembered ...." Zerubavel, supra note 6. My point is to urge that all of this is to be distinguished from the acquisition of historical knowledge. 
Now the logical space between the polar options of knowing a past event and forgetting it becomes apparent. Since memory is reflexive knowledge, there are two ways of ridding oneself of it: by losing the knowledge, or by retaining the knowledge while losing its reflexivity. Like everyone else, contemporary Brits may retain the external historical knowledge of the Napoleonic wars without its being part of their collective memory, that is, without its being the kind of internal knowledge that identifies the possessor as the subject of the known acts. Relatedly, although the British will share with everyone else a range of emotional attitudes toward the battle-perhaps admiration for the fighters' bravery or the generals' ingenuity, horror at the carnage, and the like-this range will not include emotions predicated on being a party to the battle, such as pride in the victory, or resentment against the French. We can say about such Brits that they unremember the battle without forgetting it. A British person holding this intermediate or composite cognitive position will best express it by her willingness to acknowledge, when appropriate, that the British won at Waterloo, while reluctant to affirm that "we won." At bottom, the point is really quite simple and mundane, encapsulated in the colloquial expression that many former adversaries, now reconciled, are wont to use in reference to the source of their previous acrimony: "It is all just history now.",30

But is this transposition of a past action from memory to history really tenable? It may be pointed out in opposition that when a contemporary British child reads in a history book that Britain won the battle of Waterloo, the child will reason, "I am British; hence, we won the battle. Why am I not allowed to use this expression? Why is this bit of knowledge not part of my collective identity, and hence collective memory, as a Brit?" In response, we could say something along the following lines. "Though Britain did win the battle, it does not follow that this victory is still constitutive of your British identity. Brits no longer appropriately derive shame or pride from it; they no longer enjoy the spoils nor owe amends to the French. The version of Britain as a victor has been superseded by a version in which that battle no longer plays a role. What you say is true as a matter of history, but not as a matter of memory, and your way of putting it misleadingly suggests the latter." This, after all, is my argument in a nutshell, and it ought to convince the child. One might reasonably object, however, that this reasoning will rather baffle the child and tax her mental capacities, that it is too complicated or convoluted compared to the child's own straightforward, if simplistic, reasoning. This is indeed an important objection, but its import is somewhat different than might first appear. The teaching of history and the cultivation of collective memory are related but importantly different enterprises that can be easily confounded. One implication is that

30. The process I advocate here of converting memory into history corresponds to what Halbwachs describes in terms of the loss of an organic relationship to past events. See HALBWACHS, supra note 19, at 80. It can also be seen as the flip side of the process that Yerushalmi, in his classical study of Judaism, describes as the displacement of Jewish memory by historiography since the eighteenth century. YOSEF HAYIM YERUSHALMI, ZAKHOR: JEWISH HISTORY AND JEWISH MEMORY (1982). 
some history is better taught only to adults, lest it be inadvertently transformed into memory. ${ }^{31}$

31. For related issues arising in connection with teaching history to children, see FRANCES FITZGERALD, AMERICA REVISED: HISTORY SCHOOLBOOKS IN THE TWENTIETH CENTURY (1979); YAEL ZERUBAVEL, RECOVERED ROOTS: COLlECTIVE MEMORY AND THE MAKING OF ISRAELI NATIONAL TRADITION (1995). 